\title{
As rendas de Molly Bloom
}

\section{Cibele Braga Silva*}

\begin{abstract}
Resumo: "Penélope" é o último capítulo do cânone Abstract: "Penelope" is the last episode of the modernista da língua inglesa Ulisses (1922), de James modernist canon of English literature, Ulysses (1922), Joyce. O monólogo interior de Molly Bloom é uma by James Joyce. Molly's interior monologue is a lyrical explosão lírica do universo feminino, onde o leitor é explosion of the feminine universe, where the reader is confrontado com um fluxo não-restrito de emoções e confronted with a non-restrictive flow of emotions and sentimentos, em livre-associação e total desobediência feelings, in free-association, and total disobedience of às regras gramaticais, pois não há pontuação, letras grammar rules, whereas there is no punctuation, capital maiúsculas ou apóstrofes em "Penélope". Joyce, com letters, or apostrophes in "Penelope". Joyce, with total total maestria, expressa a coragem e rebeldia da mulher mastery, expresses woman's courage and rebellion pelos lábios de Molly, levando-nos a considerar como a through Molly's lips, leading us to consider how memória, o tempo e as imagens são construídas no memory, time and images are constructed in the discurso feminino e, conseqüentemente, no discurso feminine discourse and consequently in memorialistic memorialista. discourse.
\end{abstract}

Palavras-chave: memória; tempo; imagens; discurso Keywords: memory; time; images; feminine discourse; feminino; discurso memorialista. memorialistic discourse.

O episódio de "Penélope" em Ulisses (1922), de James Joyce, é um texto recriado a partir da Odisséia (700 a.C.) de Homero. Na verdade, a protagonista feminina joyceana é uma paródia da fiel esposa de Odisseu. Acreditava-se que Odisseu já estaria morto após tantos anos em viagem pelo Mediterrâneo e, portanto, esperava-se que a rainha contraísse matrimônio para dar ao povo um novo rei. Não convencida do falecimento de seu marido Penélope usa um estratagema para enganar seus pretendentes: destece à noite todo o tecido que tecia durante o dia postergando suas segundas núpcias. Infiel ao marido, Leopold Bloom, Marion ou simplesmente Molly resgata do passado reminiscências nesse episódio. Pretendese, portanto, neste texto, analisar como o tempo, a memória e as imagens são construídas na narrativa do episódio "Penélope".

James Augustine Aloysius Joyce, com absoluta maestria, emergiu do modernismo literário europeu empreendendo grandes esforços para ultrapassar os limites do discurso tradicional. Lançou mão, conseqüentemente, da técnica de monólogo interior direto, no episódio em questão, para que o leitor mergulhasse profundamente no universo feminino. Monólogo interior direto é um tipo de fluxo de consciência em que o narrador revela os

\footnotetext{
* Mestranda em Literatura inglesa e outros sistemas semióticos na Faculdade de Letras da Universidade Federal de Minas Gerais.
} 
pensamentos, sentimentos e sensações mais íntimos de um único personagem na mesma ordem em que fluem em sua mente. $\mathrm{O}$ autor não faz qualquer comentário ou descrição para ajudar o leitor a desembaraçar essa complexa teia e muito menos tenta apresentar esse derramamento de pensamentos em frases gramaticalmente corretas ou de forma lógica nessa narrativa em primeira pessoa. O monólogo de Molly, então, serve para esclarecer ou tornar inteligíveis os elementos de duração no tempo e o aspecto de um eu perdurável, segundo Hans Meyerhoff (1976). Essa técnica é destinada a dar "uma impressão visível e sensível de como é significativo e inteligível pensar sobre o eu como uma unidade contínua a despeito da multiplicidade mais surpreendente e caótica da experiência imediata." (MEYERHOFF, 1976, p.34) Portanto a continuidade do tempo, considerada por muitos filósofos como um rio, corresponde à continuidade do fluxo da consciência do eu.

Percebe-se que o tempo da lembrança, no monólogo interior em questão, nasce e sobrepõe-se ao tempo do mundo. Apesar da perfeição das associações, há inseparabilidade da forma de seu conteúdo e a força dessa construção narrativa elimina qualquer dúvida sobre a verdade ou a semelhança dessas lembranças ou sentimentos. As aporias conceituais são então substituídas pela força persuasiva de existências, experiências e conseqüentemente de "durações" que acessam o nível de uma realidade que é diferente - e não menos real.

O episódio "Penélope" funciona no nível da inversão simbólica, relacionado ao conceito de Lacan, retomado neste ensaio a partir da leitura de Julia Kristeva (1984), em que a ordem social é representada pelo "nome do Pai" (e também pelo "não" do Pai) que garante a ordem e a aquisição da linguagem. (cf. KRISTEVA, 1984, p.26-30). A proibição simbólica é responsável pela repressão do vínculo imaginário com a mãe, que vem a efeito por meio de sons pré-verbais e imagens. KRISTEVA (1984) criou o termo semiótico para se referir à ordem fluida, caótica e pré-lingüística, na qual o contacto com a mãe é mais intenso. A ordem semiótica é, portanto, indiferente à linguagem, enigmática, feminina. (cf. KRISTEVA, 1984, p.29). Oposta ao não da proibição paterna, pode-se considerar que a ordem semiótica de Kristeva representa o sim da mãe, que é sua imagem não reprimida. Portanto Molly, durante seu monólogo, está em sua cama, de madrugada, sonolenta, em uma condição pré-verbal, semiótica aflorada. Essa condição enfraquece o senso do proibido, permitindo que seu discurso seja anárquico, fragmentado, sem regras gramaticais, letras maiúsculas, pontuação e encadeamento lógico: exemplo perfeito de monólogo interior direto.

Segundo KRISTEVA (1984), Joyce tenta conseguir alcançar o semiótico ao modificar a estrutura lingüística e produzir um texto revolucionário (KRISTEVA, 1984, p.79), que é divorciado da ordem estrita e da função simbólica. A fragmentação na linguagem evita o 
domínio da fala, característica de um discurso simbólico. Esse texto, que rompe a ordem simbólica, torna-se um meio através do qual ocorre a revolução social, posto que o autor dá ênfase a discursos que são marginalizados pelas sociedades patriarcais.

Apesar de KRISTEVA (1984), em suas explicações teóricas, se referir principalmente a Finnegans Wake (1939), texto posterior a Ulisses também de JOYCE (2005), que é freqüentemente concebido como a narrativa de um sonho o monólogo de Molly Bloom pode ser tomado como exemplo claro de expressão do semiótico na literatura. Em nenhum outro episódio em Ulisses, somos confrontados com tal fluxo de emoções e sentimentos sem restrições, em livre associação, sem a menor obediência às regras gramaticais, sem pontuação, letras maiúsculas, apóstrofes. Quando JOYCE (2005) elabora a estrutura de "Penélope" de forma peculiar, ele apresenta a intensidade de sentimentos da personagem e a desobediência aberta a qualquer regra demonstrando, assim, uma profunda compreensão da mente da mulher. $\mathrm{O}$ autor parece afirmar que esse discurso complexo e fragmentado não seria o mesmo, caso tivesse sido criado em uma mente masculina, como aqueles em que os pensamentos de Leopold Bloom e/ou Stephen Dedalus predominam, episódios mais organizados.

O fluxo de linguagem de Marion é fluido, plural, não reprimido pelas leis da sociedade (a ordem simbólica), dando vazão ao jouissance ${ }^{l}$ de Molly. Somente uma mulher poderia contar com suas próprias palavras sobre suas experiências, sendo capaz de reproduzi-las inteira e significativamente. De certa maneira, Molly torna-se a porta-voz de todas as mulheres: "eu era uma flor da montanha sim assim somos todas flores todo corpo de uma mulher sim" (JOYCE, 2005, p.813).

Todos os eventos da narrativa parecem convergir em "Penélope", o ponto de chegada para Bloom, Stephen, Joyce e até mesmo o leitor; é a última palavra neste épico moderno da vida humana. As qualidades femininas do monólogo de Molly são enfatizadas posteriormente quando o episódio é comparado ao anterior - "Íthaca" - em que a linguagem objetiva, linear e histórica assim como a narrativa são retratadas. É significativo que, ao longo do episódio "Penélope", Molly encontra-se em um único lugar fixo, enquanto Bloom e Stephen fazem suas andanças na cidade de Dublin. Esse episódio funciona, portanto, como um lar, um útero,

\footnotetext{
${ }^{1}$ A tradução mais simples é prazer ou gozo. Ver nota presente na introdução 3 do New French Feminisms: An Anthology, ed. Elaine Marks e Isabelle de Courtivron (Anherst: University of Massachussetts Press, 1980), onde há uma explicação das conotações feministas de jouissance: Este prazer, quando atribuído a uma mulher, é considerado de uma ordem diferente do prazer que é representado na economia libidinal masculina que é freqüentemente descrito em termos de um ganho capitalista e motivo de lucro. A jouissance da mulher carrega consigo a noção de fluidez, difusão, duração. Está presente no mundo do gozo, do dar, gastar, dispensar de prazer sem preocupação com os fins (p. 36, n.8). Tradução minha.
} 
o centro da narrativa e das vidas de outros personagens masculinos. Mais que Homero, é Penélope que tece e destece o seu tecido e que pode ter sido o modelo de autoridade de Joyce.

O monólogo de Molly também propõe a exaltação do corpo feminino. O mar e as flores, imagens tradicionalmente femininas, são constantemente evocados. $\mathrm{O}$ aspecto semiótico da consciência de Molly é também enfatizado pela alusão constante à sua identificação com a mãe. Sendo incapaz de se identificar completamente com o pai e a ordem simbólica, Molly permanece, de certa maneira, ligada à mãe e, conseqüentemente, ao semiótico. Os corpos e mentes femininos são considerados superiores aos dos homens: "são tão lindos claro comparados à aparência dos homens" (JOYCE, 2005, p.753), "eles [os homens] não possuem metade do caráter de uma mulher" (JOYCE, 2005, p.761). Sua consciência e exaltação do corpo feminino parecem questionar as hipóteses patriarcais acerca de as mulheres serem negativos dos homens porque nelas falta algo que os homens têm e que elas desejam ter.

O aspecto cíclico do episódio - começa e termina com a mesma palavra: Sim também alude a uma qualidade feminina. Kristeva define a subjetividade feminina em termos de dois tipos de tempo: cíclico e monumental. Tempo cíclico enfatiza a repetição, continuação, gestação, enquanto o tempo monumental se refere à eternidade, quantidade infinda e falta de temporalidade. Tempo monumental é incorporado na imagem de Madona que, em vez de morrer, ascende ao céu. Tempo cíclico e monumental também correspondem com o tempo relacionado ao semiótico em oposição ao tempo linear, que está relacionado ao tempo simbólico (cf. KRISTEVA, p.187-193). Portanto, o tempo linear está associado ao uso claro e objetivo da linguagem e, conseqüentemente, à ordem do Pai. Ao ser analisada sob essa teoria, a Penélope de Joyce é a personificação do tempo cíclico e monumental das mulheres, não somente na estrutura narrativa como também nas referências temáticas recorrentes. $\mathrm{O}$ fluxo contínuo das palavras no episódio "Penélope" encontra ressonância na repetição de várias denominações da mãe de Jesus Cristo: "Ave Maria", "Maria Santíssima”, "Virgem abençoada", "Santa Maria" e ao próprio nome de Molly: Marion (Maria).

Apesar de Molly ser infiel a Bloom, JOYCE (2005) ainda escolhe referir-se a ela como Maria (Madona). Ao tratar uma mulher "pecadora" como Virgem Maria ou, em outras palavras, ao mostrar certa independência entre oposições binárias (boa/má, pura/impura), Joyce mina os valores morais patriarcais tradicionais relativos às mulheres. Há séculos sociedades patriarcais privilegiam o mito sobre as "boas" mulheres que, ao seguirem o exemplo da Madona, representam vida, pureza e bondade. Eva, em contrapartida, é a personificação da mulher pecadora que ousou transgredir a lei do Pai ao provar do fruto da 
árvore do conhecimento do bem e do mal e, por essa razão, é punida severamente. A transgressão de Eva, entretanto, pode ser percebida como uma ação bastante positiva, posto que, ironicamente, de acordo com o texto bíblico, se Eva não tivesse desafiado a lei, o mundo provavelmente não seria o mesmo que conhecemos. Na Bíblia, é a mulher que é forte e corajosa a ponto de quebrar a lei e enfrentar as consequiências de sua decisão. Molly representa tanto Eva como Maria, que simboliza a duplicidade da natureza da mulher, que pode ser considerada, muitas vezes, contraditória. Kenner chama a atenção para a contradição presente no discurso de Molly:

[...] à medida que Penélope tece e destece a sua rede, praticamente cada juízo emitido nessas vinte e cinco mil palavras densas é, substancialmente, contradito por um juízo contrário emitido em algum outro lugar. Boylan foi soberbo, Boylan é meramente vulgar; Boylan é inadequado, perverso, trivial; Bloom tem "mais culhões" que Boylan; o prospecto de Stephen a excita, Stephen pode ter cabelos oleosos que cairão sobre seus olhos (ela espera que não: linha 1.321) Ela tem orgulho de ser mulher, ela odeia; ela irá trazer o café da manhã para Poldy, ela nem se importará, ela o jogará sobre ele? E assim por diante, como o globo terrestre girando. (GILBERT, 1957, p.170).

Ao representar Molly com essa dualidade de ser, Joyce mina as pretensões patriarcais sobre a mulher. Molly, ao desobedecer à lei no paraíso - o "não" que foi responsável pela queda de Eva no Gênesis pode significar: Transgredi a proibição simbólica e não serei punida - "sim eu disse sim eu quero Sim" (JOYCE, 1995, p.815).

É, portanto, através de uma estrutura paradoxalmente prolixa e contraditória que o texto feminino se desenvolve. Pois, segundo Lúcia Castello Branco (1984, p.141), “o furo é sempre bordejado por uma margem, por um desenho, que por sua vez contornará outros furos, bordejados por outras margens". Como uma renda, na perfeita metáfora do feminino sugerida por Ana Maria Portuga Saliba (1987):

E o que é uma RENDA? Não mais que uma linha, cordão ou fita, que contorna buracos, fazendo desenhos. Com esse contorno desfilam flores, folhas, arabescos, gregas, uma infinidade de formas, mas o buraco continua lá. E o que acontece se, por acidente, o fio é puxado? Não sobra nada dos desenhos, apenas o fio. A renda, com seus desenhos, é devolvida, em sua condição de buraco, ao espaço vazio. (SALIBA, 1987, p.31-2).

Como uma renda, a escrita feminina se desenha: com seus excessos e economias, seus detalhes e lacunas. Abordá-la é lidar com o silêncio e a tagarelice, os saltos e as voltas em torno do mesmo eixo. Deleuze crê que esse texto ocupa um lugar terceiro: o do suporte da ambigüidade, da sustentação do absurdo, da exasperação de um processo que pretende fazer da linguagem uma não-linguagem. (cf. CASTELLO BRANCO, 1989, p. 141). Nesse processo, se dá a constituição do sujeito, de seu retrato que está presente no texto. Esse retrato nada mais é que uma representação icônica da memória. 
O processo de memória, neste romance, se constrói a partir do atrito de tempos, pois ao se presentificar o passado verifica-se uma lacuna entre o passado e o presente. Posteriormente é criado, então, o processo de linguagem numa instância futura, no presente do narrador. O duplo movimento da memória que vive da reminiscência e do esquecimento, da inscrição e da rasura, do traço e da obliteração do traço, segundo Freud (cf. CATELLO BRANCO, 1983, p.35), é pensado como desmemória. Essa desmemória não passa de uma ausência, uma lacuna, uma rasura, um buraco, um nada em torno do qual a renda é tecida.

É interessante lembrar que Lacan define o feminino como um furo no discurso, como uma lacuna no tecido significante. Assim, o feminino é um furo, e o discurso feminino também é constituído de furos, brechas, lacunas, o que equivale dizer que a escrita feminina, como a renda de Molly é a representação do gozo, da morte, do real² (CASTRO, 1986, p.501). Nos volteios artísticos da narrativa do episódio "Penélope", as imagens da memória são criadas à medida que o retrato do sujeito é construído. A memória se faz nas rasuras, na tentativa absurda de se captar os fatos e sentimentos reais em um texto sem pontuação e que relembra o leitor, nos saltos da tagarelice feminina, que não se pode caminhar pelo mesmo rio duas vezes.

\section{Referências}

CASTELLO BRANCO, Lúcia. A mulher escrita. Rio de Janeiro: Casa Editorial, 1989. . A traição de Penélope. São Paulo: Ed. Abril, 1983.

CASTRO, Eliana Moura e. Psicanálise e linguagem. São Paulo, Ática, 1986.

GUIMARÃES, César. Imagens da memória: entre o legível e o visível. Belo Horizonte: Editora UFMG/POSLIT, 1997.

HUMPREY, Robert. Stream of consciousness in the modern novel. Berkeley: University of California Press, 1954.

JOYCE, James. Letters of James Joyce. v. 1. New York: The Viking Press, 1957.

Ulisses. Trad. Bernardina da Silveira Pinheiro. Rio de Janeiro: Objetiva, 2005.

. Ulysses. New York: Ramdom House, Inc., 1986.

\footnotetext{
${ }^{2}$ Refiro-me aqui ao conceito psicanalítico de real que, segundo Lacan, corresponderia ao elemento nãosimbolizado, não-representado, que não pode ser recalcado e que, portanto, se situa à margem da linguagem.
} 
KRENAK, Ailton. Antes o tempo não existia. In: NOVAES, Adauto (org.). Tempo e história. São Paulo; Companhia das Letras, 1996.

KRISTEVA, Julia. Desire in Language: A Semiotic Approach to Literature and Art. New York: Columbia University Press, 1980.

Revolution in poetic language. Trad. ROUDIEZ, Leon S. New York: Columbia University Press, 1984.

. The Kristeva Reader. Oxford: Basil Blackwell, 1986. 1980.

Women's Time. Trad. JARDINE, Alice e BLAKE, Harry. Sing, v.7, n.1, p.13-35,

LACAN, Jacques. Os complexos familiares. RJ, Jorge Zahar, 1987.

Escritos. RJ, Jorge Zahar, 1998.

MANDIL, Ram. Os efeitos da Letra: Lacan, leitor de Joyce. Belo Horizonte: UFMG, 2003.

MENDONÇA, A. S. Os diversos nomes do Pai. In: $O$ ensino de Lacan. RJ: Gryphus (Forense), 1993, p. 313-321.

MARKS, Elaine e ANHERST, Isabelle de Courtivron (ed.). New French Feminisms: An Anthology. Massachussetts: University of Massachussetts Press, 1980.

MEYERHOFF, Hans. O tempo na literatura. Trad. CAMPELLO, Myriam.. Rio de Janeiro: Editora McGraw-Hill do Brasil, 1976. In: NOVAES, Adauto (org.). Tempo e história. São Paulo; Companhia das Letras, 1996.

SALIBA, Ana Maria Portugal M. Mulher: da cortadura à bordadura. In:

Belo Horizonte: Círculo Psicanalítico de Minas Gerais, 13 (26): 31-2, mar. 1987.

SCHWARZ, Daniel R. Reading Joyce's Ulysses. New York: St. Martin's P 1987. 